\title{
Pornography Use in Adolescents and Its Clinical Implications
}

\author{
Josep M. Farré ${ }^{1}$, Angel L. Montejo ${ }^{2}{ }^{\oplus}$, Miquel Agulló ${ }^{1}$, Roser Granero ${ }^{3,4}{ }^{\circledR}$, \\ Carlos Chiclana Actis ${ }^{5,6,7}$, Alejandro Villena ${ }^{6}$, Eudald Maideu ${ }^{8}$, Marta Sánchez ${ }^{9}$, \\ Fernando Fernández-Aranda 4,10,11 (D), Susana Jiménez-Murcia 4,10,11 (D) and \\ Gemma Mestre-Bach 1,5,* \\ 1 Department of Psychiatry Psychology and Psychosomatics, Dexeus University Hospital, \\ 08028 Barcelona, Spain; psico.dex@quironsalud.es (J.M.F.); agullo.miquel@gmail.com (M.A.) \\ 2 Ital Universitario Psychiatry Department, University of Salamanca Nursing School, 37007 Salamanca, Spain; \\ amontejo@usal.es \\ 3 Departament de Psicobiologia i Metodologia de les Ciències de la Salut, Universitat Autònoma de Barcelona, \\ 08193 Barcelona, Spain; roser.granero@uab.cat \\ 4 Ciber Fisiopatología Obesidad y Nutrición (CIBERObn), Instituto de Salud Carlos III, 28925 Madrid, Spain; \\ ffernandez@bellvitgehospital.cat (F.F.-A.); sjimenez@bellvitgehospital.cat (S.J.-M.) \\ 5 Facultad de Ciencias de la Salud, Universidad Internacional de La Rioja, 26006 La Rioja, Spain; \\ carloschiclana@doctorcarloschiclana.com \\ 6 Unidad de Sexología Clínica y Salud Sexual, Consulta Dr. Carlos Chiclana, 28003 Madrid, Spain; \\ alejandrovillena@doctorcarloschiclana.com \\ 7 Departamento de Psicología, Facultad de Medicina, Universidad CEU-San Pablo, 28925 Madrid, Spain \\ 8 Hospital de Campdevanol, 17530 Girona, Spain; dr.emaideu@gmail.com \\ 9 Consorcio de Eduacación de Barcelona, 08010 Barcelona, Spain; msanc21@xtec.cat \\ 10 Department of Psychiatry, Bellvitge University Hospital-IDIBELL, 08907 Barcelona, Spain \\ 11 Department of Clinical Sciences, School of Medicine, University of Barcelona, 08007 Barcelona, Spain \\ * Correspondence: gemma.mestre.bach@gmail.com; Tel.: +93-4560111
}

Received: 30 September 2020; Accepted: 4 November 2020; Published: 11 November 2020

\begin{abstract}
Background: The Differential Susceptibility to Media Effects Model(DSMM) suggests that pornography use effects are conditional and they depend on dispositional, developmental, and social differential susceptibility variables. This framework also highlights that the differential susceptibility variables act as predictors of pornography use and as moderators of the effect of pornography on criterion variables. (2) Methods: By administering a survey to $n=1500$ adolescents, we tested whether these assumptions were met. (3) Results: Pornography use was related to being male and older, having a bisexual or undefined sexual orientation, higher substance use, being non-Muslim, and reporting sexual interest and the use of the media to obtain sexual information. Structural Equation Modeling (SEM) showed that higher levels in the criterion variables were directly related to pornography use, older age, substance use, and being women. Some mediational links also emerged. Pornography use mediated between the age and criterion variables. Moreover, substance use mediated the association between age and gender with the criterion variables. (4) Conclusions: Our findings support the clinical applicability of the theoretical DSMM framework. Knowing adolescent pornography consumers' profiles and the impact of pornography on this population would allow for the designing of more effective prevention and regulation proposals.
\end{abstract}

Keywords: sexuality; adolescents; pornography; porn; gender; risky behaviors 


\section{Introduction}

The presence of sexually explicit materials has increased significantly both in mass media and social media [1,2]. Moreover, with the emergence of the Internet, the use of pornography has become widespread throughout the world [3,4]. In the case of adolescents and young adults, recent rates of pornography use have been reported to be around $43 \%$ [5]. This increase in consumption patterns may be partly explained by the "Triple A" theory, which highlights easy access to the Internet, the fact that a large part of the population can afford it, and the anonymity that the Internet guarantees to its consumers [6].

Numerous studies have focused on evaluating the use of pornography in this age group and its association with multiple variables. Some authors have tried to define possible profiles of adolescents and young people who consume pornography. For example, Efrati et al. [7] identified that those adolescents who used pornography were usually boys, low on social intimacy, introverted and neurotic, and more overt narcissists, among other factors. In this line, Brown et al. [8] identified three types of pornography users taking into account variables such as age, pornography acceptance, use, motivations for use and religiosity - porn abstainers, auto-erotic porn users and complex porn users.

The Differential Susceptibility to Media Effects Model (DSMM) was designed by Valkenburg and Peter [9] and focuses on microlevel media effects. This model is based on multiple solid theories such as Social Cognitive Theory [10], the Neoassociationist Model [11], the Selective Exposure Theory [12], and the Media Practice Model [13]. The DSMM is structured around four central propositions: (1) Media effects are conditional and depend on dispositional, developmental, and social differential susceptibility variables. (2) Media effects are indirect and cognitive; emotional and excitative media response states mediate the relationship between media use and media effects. (3) The differential susceptibility variables act as predictors of media use and as moderators of the effect of media use on media response states. (4) Media effects are transactional; they influence media use, media response states, and differential susceptibility variables [9].

On the basis of the DSMM framework, Peter and Valkenburg [14] have published a review including studies that have evaluated pornography use in adolescents. In terms of dispositional predictors of pornography use, demographics, personality traits, norm-related variables, sexual interest, and Internet behavior have been explored [14]. It has been suggested that male adolescents are more exposed to pornography than females, although gender differences are smaller the more liberal their country of origin is [15-17]. Moreover, rule-breaking and adolescents who use substances may use pornography more frequently $[18,19]$; the same goes for adolescents with greater sexual interest [20].

Regarding developmental variables, age, pubertal maturation, and sexual experience have been studied in adolescents. There is controversy about whether pornography use increases with age, and existing studies reported conflicting results $[15,16,18]$. In studying possible trajectories of adolescent pornography use, however, it has been suggested that early puberty may be linked with earlier exposure to pornography and more frequent pornography use later [21]. The same applies to sexual experience, with some authors associating it with more frequent pornography use, while others associated it with a lower frequency $[15,20]$. Taking social variables into account, poor family functioning, desire for popularity, peer pressure, and victimization online and offline have been related with higher pornography use in adolescents [18,22-24]. In this vein, Nieh et al. [21] evaluated the influence of factors such as peer behaviors and parenting style on adolescent pornography use trajectories, finding that parental monitoring protected adolescents from pornography use. Relatedly, Efrati et al. [25] highlighted that the impact of loneliness on the frequency of pornography use may be dependent on individuals' attachment orientations. In terms of victimization, the possible association between the use of pornography and violence and sexual aggression and coercion, as well as the problematic use of pornography, have been particularly studied [26-30].

Finally, with regard to criterion variables, pornography use has been related to more permissive sexual attitudes [31-33]. However, evidence for an association between pornography use and risky sexual behaviors, such as unprotected sex, is mixed [34,35]. 
Therefore, the existing evidence on how these multiple variables interact with each other is contradictory, and to the best of our knowledge, no study has yet evaluated all the variables proposed by the DSMM. Therefore, there is still a lack of systematic data on how the multiple variables of the DSMM model interact with each other. To this end, the present study aimed to assess in an integrated way the nuclear correlates of the use of pornography in adolescents suggested by the DSMM (dispositional, developmental, social and criterion variables). For this purpose, we tested two of the four DSMM propositions: (1) we explored whether dispositional, developmental, and social variables predict pornography use; (2) we evaluated whether dispositional, developmental, and social variables may not only predict pornography use but also moderate the extent to which pornography use predicts criterion variables. We hypothesized that the explored DSMM proposals will be fulfilled.

\section{Experimental Section}

\subsection{Participants and Procedure}

An e-mail was sent to all the public and private high schools in Catalonia (Spain) that appeared on the list provided by the Catalan government. Special education centers were excluded. Of all the high schools, excluding those that did not answer or refused to participate, 14 schools were finally included, with a total of $n=1500$ adolescent students (14-18 years old). It was the principals or boards of education who gave permission to participate in the present study. The 14 high schools belonged to different geographical areas of Catalonia and included participants of different socioeconomic statuses to ensure that the results were representative.

The evaluation was carried out during the same academic year. Once the high schools showed interest, our research team went in person to explain the details of the research, resolve doubts, and specify the procedure. All the students from the same high school were evaluated on the same day by a member of the research team, together with a teacher from the high school. Besides supervising the administration of the paper-and-pencil self-administered survey, our research team addressed the potential doubts of the students. There was no financial reward. However, at the end of the sample collection, our research team returned to each high school to explain, to the boards of education, the main results of the research. It is not possible to calculate the refusal rate because some centers chose not to provide us with this information, but we estimate that it was less than $2 \%$.

\subsection{Assessment}

The survey contained 102 items assessing dispositional, developmental, social, criterion, and media use variables. The items included have not been evaluated for their psychometric properties. Due to practical issues of time and adolescent fatigue, we decided to design items to evaluate the variables of interest instead of using validated psychometric instruments, which are much more extensive.

\subsubsection{Dispositional Variables}

Dispositional variables included: sociodemographic, norm-related, and sexual interest variables-Internet behavior variables. The sociodemographic variables assessed in the survey were gender and sexual orientation. Drug use and religion were evaluated in the category of norm-related features. Frequency of drug use was coded into one of four categories: non-consumption, once a month or less, between twice a month and once a week, and more than once a week.

\subsubsection{Developmental Variables}

Developmental variables included age and sexual experience. Sexual experience assessed aspects such as the age of their first sexual experience and the current frequency of sexual intercourse. 


\subsubsection{Social Variables}

Social variables contained family-related factors and victimization. Family-related factors included items related to the adolescent's nuclear family and the possible presence of siblings. The victimization section evaluated sexual assault, malpractice during sexting, and online victimization.

\subsubsection{Criterion Variables}

Criterion variables assessed the following domains: risky sexual behaviors (such as unprotected sex, and sex after alcohol and substance use), and permissive sexual attitudes (such as infidelity).

\subsubsection{Media Use}

Survey items measured pornography use and related sexual behaviors, sexting, and cybersex behaviors with responses coded dichotomously as "yes/no".

\subsection{Statistical Analysis}

Statistical analysis was carried out with Stata16 for Windows [36]. A logistic regression fitted predictive models of the pornography media use. Different logistic models were fitted for each of the variables defined as dependent variables (downloading sexual content, use of social nets to send sex content, participation in sexual chats and use of erotic lines). The set of the potential predictors included all the other variables analyzed for this work (dispositional variables (sex, sexual orientation, drug use/abuse, brought up following a religion, religious practitioner, feeling religious, interest in social nets for obtaining sexual content), developmental variables (age, age at first sexual experience and frequency of sexual experiences), and social variables (persons living at home, being abused and being forced to share sex content)). A stepwise method was used to build a final model in which the choice and selection of the significant predictors is carried out by an automatic procedure, adding or removing in subsequent steps the predictors according to pre-specified parameters. This method is particularly useful in studies with a large set of potential independent variables and no underlying empirical hypothesis on which to base the model selection. For categorical independent variables, different contrasts were defined: pairwise comparisons for nonordered variables and polynomial contrasts for ordered variables (polynomial post-hoc tests are particularly useful to determine whether a particular mathematical pattern emerges for the levels of the predictor, such as linear, quadratic, cubic or quartic levels) [37]. Adequate goodness of fit for the final models was considered for nonsignificant results $(p>0.05)$ in the Hosmer-Lemeshow test. Nagelkerke's R-squared coefficient $\left(\mathrm{N}-\mathrm{R}^{2}\right)$ estimated the global predictive capacity, considering null for $\mathrm{N}-\mathrm{R}^{2}<0.02$, low-poor for $\mathrm{N}-\mathrm{R}^{2}>0.02$, mild-moderate for $N-R^{2}>0.13$, and high-good for N-R $>0.26$ [38]. The area under the receiver operating characteristic (ROC) curve (AUC) measured the discriminative capacity (AUC $<0.65$ was interpreted as low-poor, AUC $>0.65$ mild-moderate, and AUC $>0.70$ high-good [39]).

Path analysis was used to describe the underlying mechanisms explaining the pornography use based on the set of variables registered in this work. Path analysis procedures represent a straightforward extension of multiple regression modeling, which allows estimating the magnitude and significance level of associations into a set of variables, including mediational links [40]. This procedure can be used for both exploratory and confirmatory modeling, and therefore it allows theory testing and theory development $[41,42]$. In this work, and due to the existence of multiple criteria measures, we defined a latent variable defined by the observed indicators contraception, unprotected sex, emergency contraception, practicing sex after alcohol use/abuse, practicing sex after drugs use/abuse and infidelity (the latent variable in this study allowed us to simplify the data structure and therefore facilitated a more parsimonious fitting) [43]. In this study, path analysis was adjusted through Structural Equation Modeling (SEM), using the maximum-likelihood estimation for the parameter estimation, and valuing the goodness of fit through the standard statistical measures: the root mean square error of approximation (RMSEA), Bentler's Comparative Fit Index (CFI), the Tucker-Lewis 
Index (TLI), and the standardized root mean square residual (SRMR). An adequate fit was considered for models meting the next criteria Barret [44]: RMSEA $<0.08$, TLI $>0.90$, CFI $>0.90$, and SRMR $<0.10$. The global predictive capacity of the model was measured by the coefficient of determination (CD), whose interpretation is similar to global $R^{2}$ in multivariate regression models.

\subsection{Ethics}

The Hospital Ethics Committee (Comité Ético de Investigación Clínica del Grupo Hospitalario Quiron) approved the procedures of this study (REF: 012/107) in December 2014. The present study was carried out in accordance with the latest version of the Declaration of Helsinki. We obtained a permit from the management boards of each school that agreed to participate in our study. Each school provided the parents or legal guardians of underage students with information about the study. Those parents or minors who did not wish to participate informed the school board. It was clarified that participation was voluntary and they could withdraw at any time. The data of $n=1$ student were withdrawn from the study after the request of the school board.

\section{Results}

\subsection{Characteristics of the Sample}

Table 1 includes the distribution for the variables analyzed in the study. Most individuals reported heterosexual orientation (90.5\%), while $2.1 \%$ indicated that they were homosexual, $3.9 \%$ bisexual, and 3.6\% not defined. The percentage of individuals brought up Catholic was 36.1\%, Muslim 4.9\%, and other religions 5.3\% (the remaining 53.8\% indicated that they were atheist). Only $10.7 \%$ described themselves as a religious practitioner, with $17.0 \%$ being religious or very religious. Around $20 \%$ of the sample reported substance use or abuse. The percentage of adolescents who reported sexual interest and the use of the media to obtain sexual information was $25.6 \%$.

The proportion of individuals with sexual experience was around $33 \%$, with $15-16$ years old being the most likely age of sexual initiation. The prevalence of adolescents who indicated being victims of sexual abuse was $6.5 \%$, while $17.6 \%$ indicated that they had been forced to share sexual content.

Regarding media use, $43.6 \%$ reported pornography use. Other related behaviors showed lower percentages (between $6.1 \%$ for use of erotic telephone lines and $9.5 \%$ for downloading sexual content). The criterion variables were distributed as follows: $31.0 \%$ used contraception, $17.3 \%$ reported unprotected sex, and $8.7 \%$ used emergency contraception; sexual behavior after alcohol use was reported by $29.9 \%$ of the participants, while sex after substance use was reported by $11.7 \%$. The percentage of adolescents who reported being unfaithful was $15.7 \%$.

\subsection{Predictive Models of Pornography Use}

Table 2 contains the results of the logistic regression, selecting the best predictors of pornography use in the study. This model achieved adequate fitting ( $p=0.385$ in the Hosmer-Lemeshow test), large predictive capacity $\left(\mathrm{N}-\mathrm{R}^{2}=0.32\right)$, and large discriminative capacity (AUC $=0.79$ ). Increases in the odds of pornography use were related to being male, older, bisexual or with undefined sexual orientation, higher substance use, and reporting sexual interest and the use of the media to obtain sexual information; in addition, being Muslim (compared to being atheist) decreased the likelihood of pornography use. 
Table 1. Descriptive variables of the study $(n=1500)$

\begin{tabular}{|c|c|c|c|c|c|c|c|}
\hline \multicolumn{2}{|c|}{ Dispositional Variables } & \multirow{3}{*}{$\begin{array}{c}n \\
833 \\
667\end{array}$} & \multirow{3}{*}{$\begin{array}{c}\% \\
55.5 \% \\
44.5 \%\end{array}$} & \multicolumn{2}{|c|}{ Social Variables } & \multirow{3}{*}{$\begin{array}{c}n \\
1424 \\
40\end{array}$} & \multirow{3}{*}{$\begin{array}{c}\% \\
94.9 \% \\
2.7 \%\end{array}$} \\
\hline & Female & & & \multirow{3}{*}{ Living with ... } & Both parents & & \\
\hline Gender & Male & & & & Other family & & \\
\hline \multirow{4}{*}{ Sexual orientation } & Heterosexual & 1357 & $90.5 \%$ & & Other & 36 & $2.4 \%$ \\
\hline & Homosexual & 31 & $2.1 \%$ & \multirow{4}{*}{ Living with ... } & 0 Siblings & 350 & $23.3 \%$ \\
\hline & Bisexual & & $3.9 \%$ & & 1 sibling & 818 & $54.5 \%$ \\
\hline & Not defined & 54 & $3.6 \%$ & & 2 siblings & 229 & $15.3 \%$ \\
\hline \multirow{4}{*}{ Substance use/abuse } & Never & 1212 & $80.8 \%$ & & 3 or more siblings & 103 & $6.9 \%$ \\
\hline & $1 \times /$ month or less & 126 & $8.4 \%$ & \multirow{2}{*}{ Sexual abuse } & No & 1403 & $93.5 \%$ \\
\hline & $2 \times /$ month or $1 \times /$ week & 75 & $5.0 \%$ & & Yes & 97 & $6.5 \%$ \\
\hline & $3 \times$ or more/month, or weekly & 87 & $5.8 \%$ & \multirow{2}{*}{ Forced to share sexual content } & No & 1236 & $82.4 \%$ \\
\hline \multirow{4}{*}{ Brought up in a religion } & Atheist & 807 & $53.8 \%$ & & Yes & 264 & $17.6 \%$ \\
\hline & Catholic & 541 & $36.1 \%$ & \multicolumn{4}{|c|}{ Pornography media use } \\
\hline & Muslim & 73 & $4.9 \%$ & Pornography use & Yes & 654 & $43.6 \%$ \\
\hline & Other & 79 & $5.3 \%$ & Social media to send sex content & Yes & 112 & $7.5 \%$ \\
\hline \multirow{2}{*}{ Religious practitioner } & No & 1339 & $89.3 \%$ & Social media to send self-sex. & Yes & 98 & $6.5 \%$ \\
\hline & Yes & 161 & $10.7 \%$ & Participation in sexual chats & Yes & 93 & $6.2 \%$ \\
\hline \multirow{4}{*}{ Religious feeling } & None & 936 & $62.4 \%$ & Use of erotic telephone lines & Yes & 91 & $6.1 \%$ \\
\hline & A little religious & 308 & $20.5 \%$ & Downloading sexual content & Yes & 143 & $9.5 \%$ \\
\hline & Religious & 218 & $14.5 \%$ & \multicolumn{4}{|c|}{\begin{tabular}{|c|c|} 
Criterion variables \\
\end{tabular}} \\
\hline & Very religious & 38 & $2.5 \%$ & Use of contraception & Yes & 465 & $31.0 \%$ \\
\hline \multirow{2}{*}{$\begin{array}{l}\text { Sexual interest/Internet } \\
\text { behavior }\end{array}$} & No & 1116 & $74.4 \%$ & Unprotected sex & Yes & 260 & $17.3 \%$ \\
\hline & Yes & 384 & $25.6 \%$ & Use of emergency contraception & Yes & 130 & $8.7 \%$ \\
\hline \multirow{6}{*}{ Age } & Developmental variables & & & Sex after alcohol & Yes & 449 & $29.9 \%$ \\
\hline & 14 years & 117 & $7.8 \%$ & Sex after other substances & Yes & 176 & $11.7 \%$ \\
\hline & 15 years & 340 & $22.7 \%$ & Infidelity & Yes & 236 & $15.7 \%$ \\
\hline & 16 years & 360 & $24.0 \%$ & Infidelity: caresses & Yes & 145 & $9.7 \%$ \\
\hline & 17 years & 454 & $30.3 \%$ & Infidelity: kisses & Yes & 41 & $2.7 \%$ \\
\hline & 18 years & 229 & $15.3 \%$ & Infidelity: embraces & Yes & 221 & $14.7 \%$ \\
\hline
\end{tabular}


Table 1. Cont.

\begin{tabular}{|c|c|c|c|c|c|c|c|}
\hline \multicolumn{2}{|c|}{ Dispositional Variables } & \multirow{2}{*}{$\frac{n}{16.23}$} & \multirow{2}{*}{$\begin{array}{c}\% \\
1.18\end{array}$} & \multicolumn{2}{|c|}{ Social Variables } & \multirow{2}{*}{$\begin{array}{c}n \\
58\end{array}$} & \multirow{2}{*}{$\begin{array}{c}\% \\
3.9 \%\end{array}$} \\
\hline \multirow{5}{*}{ First sexual experience at } & Mean-SD & & & Infidelity: oral sex & Yes & & \\
\hline & Never & 1008 & $67.2 \%$ & Infidelity: masturbation & Yes & 143 & $9.5 \%$ \\
\hline & Under 13 & 20 & $1.3 \%$ & Infidelity: penetration & Yes & 44 & $2.9 \%$ \\
\hline & 13-14 years & 130 & $8.7 \%$ & & & & \\
\hline & $15-16$ years & 284 & $18.9 \%$ & & & & \\
\hline \multirow{6}{*}{$\begin{array}{l}\text { Frequency of sexual } \\
\text { experience }\end{array}$} & $17-18$ years & 58 & $3.9 \%$ & & & & \\
\hline & Never & 1012 & $67.5 \%$ & & & & \\
\hline & Only 1 time & 64 & $4.3 \%$ & & & & \\
\hline & $2-5$ times & 99 & $6.6 \%$ & & & & \\
\hline & 6-10 times & 55 & $3.7 \%$ & & & & \\
\hline & More than 10 times & 270 & $18.0 \%$ & & & & \\
\hline
\end{tabular}


Table 2. Predictive models of pornography use: stepwise logistic regression $(n=1500)$.

\begin{tabular}{|c|c|c|c|c|c|c|c|}
\hline \multicolumn{8}{|c|}{$\begin{array}{l}\text { Criterion: Pornography Use. } \\
\text { Fitting Indexes: } \mathrm{H}-\mathrm{L}\left(p \text {-Value) }=0.385 ; \mathrm{N}-\mathrm{R}^{2}=318 ; \mathrm{AUC}=0.790 \text { (95\% CI: } 0.767 \text { to } 0.813 \text { ) }\right.\end{array}$} \\
\hline Predictor & Contrast & B & SE & $p$ & OR & \multicolumn{2}{|c|}{$95 \% \mathrm{CI}$} \\
\hline Sex & Male vs. Female & 2.122 & 0.128 & $<0.001$ & 8.349 & 6.503 & 10.720 \\
\hline \multirow[t]{4}{*}{ Sexual orientation } & & & & 0.019 & & & \\
\hline & Homosex. vs. Heterosex. & 0.221 & 0.425 & 0.603 & 1.247 & 0.543 & 2.867 \\
\hline & Ambisex. vs. Heterosex. & 0.702 & 0.307 & 0.022 & 2.019 & 1.107 & 3.682 \\
\hline & Non-defined vs. Heterosex. & 0.738 & 0.324 & 0.023 & 2.092 & 1.108 & 3.949 \\
\hline \multirow[t]{4}{*}{ Drugs use/abuse } & & & & 0.003 & & & \\
\hline & Linear trend & 0.413 & 0.192 & 0.032 & 1.511 & 1.036 & 2.202 \\
\hline & Quadratic trend & -0.364 & 0.214 & 0.088 & 0.695 & 0.457 & 1.056 \\
\hline & Cubic trend & -0.113 & 0.233 & 0.627 & 0.893 & 0.566 & 1.410 \\
\hline \multirow[t]{4}{*}{ Brought up in religion } & & & & 0.064 & & & \\
\hline & Catholic vs. Atheist & 0.028 & 0.131 & 0.832 & 1.028 & 0.796 & 1.328 \\
\hline & Muslim vs. Atheist & -0.771 & 0.300 & 0.010 & 0.463 & 0.257 & 0.833 \\
\hline & Other vs. Atheist & -0.159 & 0.274 & 0.562 & 0.853 & 0.498 & 1.460 \\
\hline $\begin{array}{l}\text { Sexual interest/Internet } \\
\text { behavior }\end{array}$ & Yes vs. No & 0.747 & 0.139 & $<0.001$ & 2.112 & 1.608 & 2.773 \\
\hline Age (years-old) & & 0.252 & 0.053 & $<0.001$ & 1.287 & 1.159 & 1.429 \\
\hline
\end{tabular}

H-L: Hosmer-Lemeshow. N-R²: Nagelkerke's pseudo-R ${ }^{2}$ coefficient. AUC: Area under the ROC curve. B: Logistic parameter. SE: Standard error. OR: odds ratio. 
Table 3 contains the results of the logistic models obtained for the other predictors of the pornography use and cybersex behaviors analyzed in this work. Downloading sexual content was most probable for males, those with a bisexual orientation, those reporting sexual interest and the use of social networks to obtain information regarding sex and earlier first sexual experiences. The use of social media to send sexual content was more likely for males, those who use drugs, those with sexual interest who use social media to obtain information about sex, and those who had been sexually abused by adults or other adolescents. The use of social media to send sexual content to others was related to bisexual orientation, sexual interest and the use of social media to obtain sexual information, earlier first sexual experiences, being a victim of sexual abuse, and being forced to share sexual content. The odds of participation in sexual chats was higher for males, those with sexual interest, those who use social media to obtain sexual information and those who have been forced to share sexual content. Finally, the use of erotic telephone lines was higher for men, participants with higher substance use, younger respondents, and those with a higher frequency of sexual experiences.

\subsection{Path Analysis}

Figure 1 includes the path diagram with the standardized coefficients obtained in the SEM, in which only significant parameters were retained (only relationships with significance levels $p<0.05$ are plotted). Figure 1 uses conventional rules for path diagrams and SEM schemes; the observed variables are drawn by rectangular boxes, while the latent variable is represented by a circular/elliptical shape. The final model obtained in this work met the criteria of all goodness-of-fit indexes: RMSEA $=0.062$, $\mathrm{CFI}=0.922, \mathrm{TLI}=0.901$, and SRMR $=0.050$. In addition, a large global predictive capacity was obtained for the model $(C D=0.31)$.

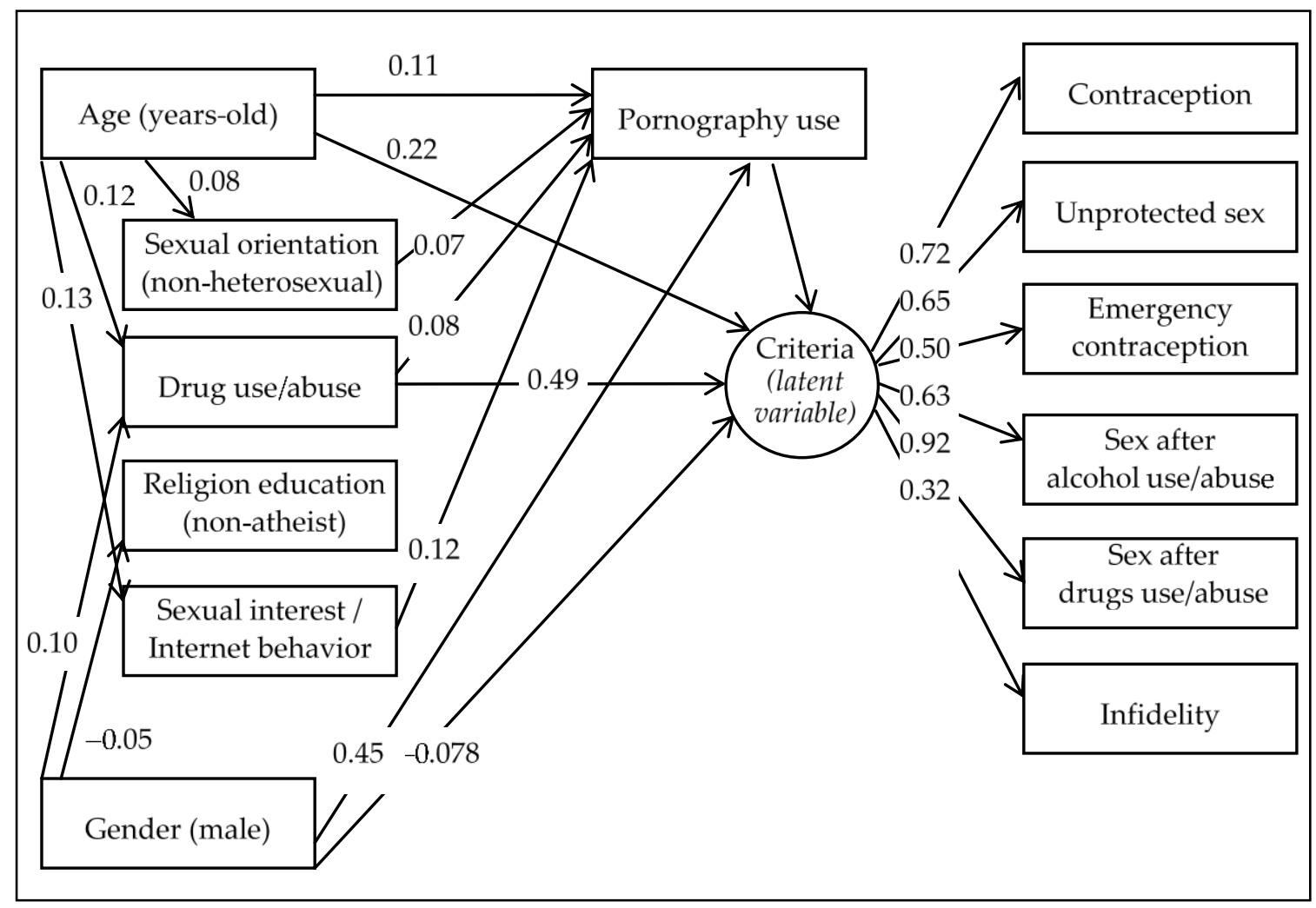

Figure 1. Path diagrams: standardized coefficients in the Structural Equation Modeling (SEM) $(n=1500)$. Note: Only significant parameters were retained in the model. 
Table 3. Predictive models of pornography use and cybersex behaviors: stepwise logistic regression $(n=1500)$.

\begin{tabular}{|c|c|c|c|c|c|c|c|}
\hline \multicolumn{8}{|c|}{$\begin{array}{l}\text { Criterion: Downloading Sexually Explicit Material. } \\
\text { Fitting Indexes: } \mathrm{H}-\mathrm{L}(p \text {-Value })=0.193 ; \mathrm{N}-\mathrm{R}^{2}=0.155 ; \mathrm{AUC}=0.748(95 \% \mathrm{CI}: 0.709 \text { to } 0.787)\end{array}$} \\
\hline Predictor & Contrast & B & SE & $p$ & OR & \multicolumn{2}{|c|}{$95 \% \mathrm{CI}$} \\
\hline Sex & Male vs. Female & 1.554 & 0.211 & $<0.001$ & 4.730 & 3.126 & 7.157 \\
\hline Sexual orientation & & & & 0.011 & & & \\
\hline \multirow{9}{*}{$\begin{array}{l}\text { Sexual interest/Internet beh. } \\
\text { 1st sexual experience at age ... }\end{array}$} & Homosex.vs. Heterosex. & -0.774 & 0.761 & 0.309 & 0.461 & 0.104 & 2.050 \\
\hline & Ambisex. vs. Heterosex. & 1.147 & 0.372 & 0.002 & 3.149 & 1.519 & 6.530 \\
\hline & Non-defined vs. Heterosex. & -0.293 & 0.560 & 0.601 & 0.746 & 0.249 & 2.235 \\
\hline & Yes vs. No & 0.916 & 0.191 & $<0.001$ & 2.498 & 1.718 & 3.632 \\
\hline & & & & 0.006 & & & \\
\hline & Linear trend & 0.222 & 0.289 & 0.442 & 1.249 & 0.709 & 2.200 \\
\hline & Quadratic trend & -0.053 & 0.297 & 0.858 & 0.948 & 0.530 & 1.697 \\
\hline & Cubic trend & 1.086 & 0.360 & 0.003 & 2.961 & 1.462 & 5.997 \\
\hline & Quartic trend & -0.561 & 0.347 & 0.106 & 0.571 & 0.289 & 1.126 \\
\hline & $\begin{array}{l}\text { Criterion: usi } \\
\text { Fitting indexes: H-L }(p \text {-value })=\end{array}$ & $\begin{array}{l}\text { cial medic } \\
N-R^{2}=0\end{array}$ & $\begin{array}{l}\text { d sexua } \\
\mathrm{UC}=0\end{array}$ & it. & & & \\
\hline Predictor & & B & SE & $p$ & OR & \multicolumn{2}{|c|}{$95 \% \mathrm{CI}$} \\
\hline Sex & Male vs. Female & 0.989 & 0.221 & $<0.001$ & 2.690 & 1.744 & 4.149 \\
\hline \multirow[t]{4}{*}{ Drugs use/abuse } & & & & 0.022 & & & \\
\hline & Linear trend & 0.415 & 0.260 & 0.111 & 1.514 & 0.909 & 2.523 \\
\hline & Quadratic trend & 0.025 & 0.320 & 0.936 & 1.026 & 0.548 & 1.920 \\
\hline & Cubic trend & 0.603 & 0.368 & 0.101 & 1.827 & 0.889 & 3.755 \\
\hline \multirow{2}{*}{$\begin{array}{l}\text { Sexual interest/Internet behavior } \\
\mathrm{He} / \mathrm{she} \text { has been abused }\end{array}$} & Yes vs. No & 1.705 & 0.210 & $<0.001$ & 5.504 & 3.647 & 8.306 \\
\hline & Yes vs. No & 1.372 & 0.308 & $<0.001$ & 3.943 & 2.156 & 7.210 \\
\hline \multirow{7}{*}{$\begin{array}{c}\text { Predictor } \\
\text { Sexual orientation }\end{array}$} & Criterion: using & 1 media to & elf-sexi & rial. & & & \\
\hline & Fitting indexes: $\mathrm{H}-\mathrm{L}(p$-value $)=$ & $N-R^{2}=0$ & $\mathrm{UC}=0$ & $\%$ CI: 0.74 & & & \\
\hline & & B & SE & $p$ & OR & \multirow{2}{*}{\multicolumn{2}{|c|}{$95 \% \mathrm{CI}$}} \\
\hline & & & & 0.001 & & & \\
\hline & Homosex. vs. Heterosex & 0.842 & 0.560 & 0.133 & 2.320 & 0.774 & 6.960 \\
\hline & Ambisex. vs. Heterosex & 1.289 & 0.360 & $<0.001$ & 3.630 & 1.791 & 7.356 \\
\hline & Non-defined. vs. Heterosex. & 0.750 & 0.464 & 0.106 & 2.116 & 0.853 & 5.252 \\
\hline Sexual interest/Internet behavior. & Yes vs. No & 1.295 & 0.225 & $<0.001$ & 3.650 & 2.349 & 5.669 \\
\hline
\end{tabular}


Table 3. Cont.

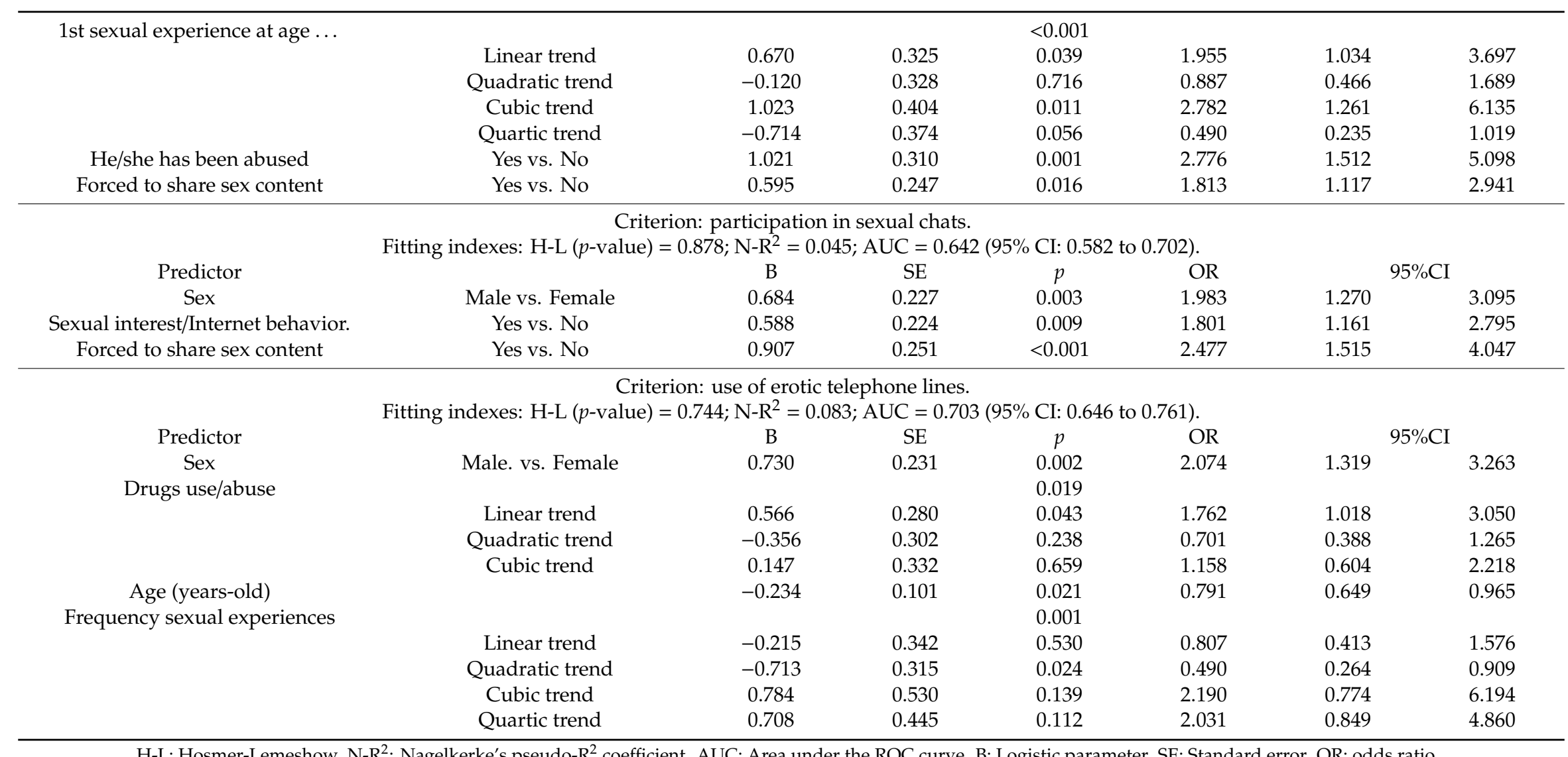

H-L: Hosmer-Lemeshow. N-R ${ }^{2}$ Nagelkerke's pseudo-R ${ }^{2}$ coefficient. AUC: Area under the ROC curve. B: Logistic parameter. SE: Standard error. OR: odds ratio. 
All the variables used for defining the latent variable in this study (labeled as "criteria" in the path diagram, Figure 1) achieved high and significant coefficients, the highest score being for practicing sex after substance use/abuse (0.92) and the lowest for infidelity (0.32). The positive coefficients achieved in all the variables defining this latent variable indicate that higher scores in the latent class are indicative of a higher number of behaviors related with risky sexual practices (a high level in the latent variable indicates a high likelihood of contraception use, unprotected sex, emergency contraception, sex practices after alcohol use/abuse, sex practices after drugs use/abuse and infidelity).

The higher levels in the criterion are directly related to pornography use, older age, substance use, and being female. Some mediational links also emerged. Firstly, pornography use mediated between age and criterion variables, as well as between sexual orientation, substance use, and sexual interest and the use of media to obtain information regarding sex with criterion variables. Secondly, substance use also mediated in the correlation between age and gender with the criterion variables. Religious education did not achieve direct/indirect contribution on the pornography use and on the latent variable.

\section{Discussion}

The purpose of this research was two-fold: (1) to explore whether dispositional, developmental, and social variables predict pornography use; (2) to evaluate whether these variables not only predict pornography use but also moderate the extent to which pornography use predicts criterion variables.

Regarding dispositional variables, sexual orientation is a relevant multidimensional construct that has been widely evaluated in the adult population $[45,46]$. However, the prevalence of sexual minority identity has rarely been examined in adolescents [47]. In the present study, $6 \%$ of the sample identified as lesbian, gay, or bisexual (LGB) and 3.6\% did not define their sexual orientation. These percentages are not far removed from previous studies. For example, Li et al. [48] found that approximately $4 \%$ of adolescents self-identified as LGB, while $14 \%$ were unsure of their sexual orientation.

When examining norm-related features, also included in the dispositional variables, religiosity seems to be another factor related to adolescent sexuality [49]. In the present study, the percentage of Catholic adolescents was 36.1\%, Muslims was $4.9 \%$, and other religions was $5.3 \%$. Other studies that have evaluated religiosity and sexuality in adolescents have found much higher rates of religiosity. For example, $83 \%$ of the adolescents in Mexico report being Catholic [50]. The prevalence is closely linked to the history and culture of each country, making it difficult to generalize. In conjunction, substance use reduces social inhibition and is associated with increased risk-taking behaviors, especially in the area of sexuality [51,52]. In adolescent populations, rates of substance use are very heterogeneous and range from $0.4 \%$ to $46 \%$ [53-56]. These results coincide with our findings, given that around $20 \%$ of our sample reported substance use or abuse.

Finally, sexual interest has also been considered as a dispositional variable in the present study. The percentage of adolescents who reported sexual interest and who used digital media to obtain sexual information was $25.6 \%$. Studies in this field have detected an increase in searching for information on sex among adolescents since the emergence of the Internet [57]. In addition, there seems to be an association between those adolescents who engage in more risky sexual behaviors and the likelihood of seeking this type of information on the Internet [58]. Some of the barriers that adolescents report when doing this type of search are the overabundant content that is difficult to filter out, as well as complaints about unintentional exposure to sexually explicit content during these searches [59].

With respect to developmental variables, the proportion of individuals in the present study with sexual experience was around $33 \%$, a figure similar to the $28.1 \%$ reported in previous studies [60]. Moreover, 15-16 years old was the most frequent age of initiation of sexual behavior in our sample. Other studies in this line have reported ages of sexual initiation around 12.8-14 years old [61]. These differences could be due to multiple causes. As some authors suggested, early sexual initiation may be influenced by factors such as alcohol use, the involvement of chat rooms or dating websites, 
and the use of medication for mental problems [62,63]. However, although the percentages vary, all comprise early sexual initiation ( $<16$ years old) [64].

Regarding social variables, and victimization more specifically, $6.5 \%$ of the adolescents reported being victims of sexual abuse. The rate of sexual abuse or assault in other European countries is about $14.6 \%$ [65]. Although it is a more common problem among adolescent females, there is a growing recognition that sexual victimization is also a relevant, though invisible, issue among male adolescents [66,67]. In this line, $17.6 \%$ of our sample reported being forced to share sexual content through social media. This pressure and the diffusion of sexual content without consent derived from sexting, as well as other online victimization behaviors such as revenge porn, cyberbullying, and online dating violence, are increasingly present in the adolescent population $[68,69]$. Titchen et al. [70] observed that more than three times as many girls as boys felt pressured to send a sext. They also found an association between sexual abuse and sexting in both sexes, thus suggesting that sexual abuse may lead to early sexualization.

Finally, with regard to media use, $43.6 \%$ of adolescents reported the use of pornography, $9.5 \%$ reported downloads of sexually explicit materials, and $6.1 \%$ engaged in phone sex. The pornography use prevalence was similar to other studies, which reported it to be around $43 \%$ [5]. However, these percentages are much lower than those found by other studies in adolescents and young adults, which ranged from $80 \%$ to $96 \%$ [71-73].

As the DSMM suggests [9], dispositional, developmental, and social variables were related to pornography use in our study. More specifically, increases in the odds of pornography use were associated with being male, older, bisexual or with an undefined sexual orientation, substance use, not being Muslim, and higher sexual interest and use of social media to obtain sexual information. These findings are consistent with other studies highlighting that male and female adolescents differ in their patterns of consumption of pornography $[74,75]$. This could be partially explained by the greater tendency of males to rate sexual stimuli as more pleasant and arousing and to show stronger neural responses derived from exposure to these sexual stimuli [76,77]. However, a slight increase in female pornography use over time has been identified $(28 \%$ in the 1970 s vs. $34 \%$ in the 2000s) [78]. Studies exploring the reasons for these sexual differences in pornography use are still very scarce. However, some authors have suggested that some factors may promote female pornography use, such as the rise of feminist porn with less aggressive content, younger age, absence of religiosity, and higher education levels [78,79]. Sexual orientation has also been a factor associated with pornography use. Our findings corroborate previous studies suggesting greater pornography use by bisexual than by heterosexual adolescents $[35,80]$. However, most studies do not assess sexual orientation or focus only on heterosexual adolescents [14]. Therefore, more research is needed, including with under-represented sexual minorities. A significant association was also found between pornography use and substance use, which is consistent with previous findings [19,81]. Some authors suggest that this correlation may be influenced by factors such as high sensation-seeking levels [81]. Considering the link between religion and pornography use, numerous studies have been based on moral incongruence [82,83]. This addresses the incompatibility between pornography use and an individual's deeply held values and beliefs about the inappropriateness of that behavior [84]. Pornography use seems to be lower with higher levels of religious attendance, especially among male adolescents, and religious attendance weakens age-based increases in pornography use for both sexes [85].

In addition, we studied whether pornography use predicted criterion variables through SEM, as proposed by the DSMM [9]. We observed a direct association between pornography and the following criterion variables: contraception, unprotected sex, emergency contraception, sex after alcohol and other substances, and infidelity. Pornography is associated with a greater tendency to engage in risky sexual behavior, such as sex under the influence of alcohol and other substances, or the use of emergency contraception. These findings corroborate that exposure to pornography may affect psychosexual development in adolescents. More specifically, pornography could lead to more permissive sexual 
values and changes in sexual behavior, such as an increase in risky sexual behaviors $[31,86]$. However, these are controversial findings that should be interpreted with caution. Other studies have failed to find an association between exposure to pornography and risky sexual behaviors such as multiple sexual partners, history of pregnancies, or early sexual initiation [35].

\subsection{Clinical Implications}

Although interest in sexuality and pornography use in adolescence has been increasing in recent years, there are still few studies that evaluate the association between these factors and other relevant aspects of this stage of development. It is essential, therefore, to have studies that attempt to design and test theoretical models that allow for the conceptualization and identification of possible phenotypes associated with the use of pornography in adolescents.

Furthermore, to date, the distance between the research and clinical fields is marked, so an approach is required that favors adequate care for adolescents who demand help for problematic pornography use.

At the clinical level, it will be of interest to assess the use of pornography in clinical evaluations in order to determine how pornography may be influencing adolescent psychosexual development. In addition, if the person is frequently using pornography, the sexual lifestyle and quality of life, as well as possible sexual risk behaviors, should be taken into account. Problematic pornography use may also be associated with other psychiatric conditions, so detecting them may help to address the consequences of these conditions. In this line, assessing adolescent pornography use can help to detect early maladaptive personality traits, such as high novelty seeking or reward dependence.

An adequate understanding of the interaction between these multiple variables associated with the use of pornography would allow clinical professionals to carry out better prevention, early detection and diagnosis of problems related to adolescent sexuality. Correctly detecting predisposing and precipitating factors of pornography use, as well as possible consequences of pornography use, could also help clinicians to differentiate between pornography use and problematic pornography use, a construct that is becoming increasingly important, both in the clinical setting and in the research field.

Finally, addressing issues of sexuality in adolescence would reduce the incidence of problems with sexual function and/or hypersexuality in adulthood, the prevalence of which appears to be increasing.

\subsection{Limitations}

The results of this study should be considered in light of its limitations. First, the cross-sectional design of the study does not allow for the determination of causal relationships or changes in patterns of adolescent pornography use. Second, the sample is not representative of the entire country, so caution should be exercised when generalizing the results. Third, the survey included many dichotomous items and was not based on validated psychometric questionnaires, which could limit the accuracy of the data obtained. Furthermore, the survey did not provide a specific definition of pornography, which could lead to different interpretations of the term. Fourth, despite the fact that adolescents knew that the evaluation was completely anonymous, when it comes to sexuality we must not forget a possible social desirability bias. Fifth, apart from substance abuse, no common psychopathology was assessed in the adolescent population, such as the presence of behavioral addictions. Finally, the frequency of pornography use was not evaluated, so we were not able to distinguish cases of problematic pornography use.

\section{Conclusions}

Our findings support the clinical applicability of the theoretical DSMM framework. Therefore, dispositional, developmental, and social variables may predict pornography use and may moderate the extent to which pornography uses predicts criterion variables. However, it must be taken into account that not all the variables included in the study had the same relevance in this association. Furthermore, the literature in this field is extremely controversial. Therefore, more studies and a longitudinal design would be necessary to define the profile of adolescent consumers of pornography. 
Knowing in depth the impact of pornography on this population would also allow for the design of more effective prevention and regulation proposals.

Author Contributions: Conceptualization, J.M.F., M.A., M.S. and G.M.-B.; Data curation, R.G.; Formal analysis, R.G.; Investigation, J.M.F., A.L.M., M.A. and G.M.-B.; Methodology, C.C.A., A.V., E.M., M.S., F.F.-A., S.J.-M. and G.M.-B.; Project administration, J.M.F. and G.M.-B.; Software, R.G.; Supervision, G.M.-B.; Writing-original draft, R.G., F.F.-A., S.J.-M. and G.M.-B.; Writing-review and editing, A.L.M., R.G., C.C.A., A.V. and G.M.-B. All authors have read and agreed to the published version of the manuscript.

Funding: Financial support was received through the Asociación Española de Sexualidad y Salud Mental (AESEXSAME/2015), the Ministerio de Ciencia, Innovación y Universidades (grant RTI2018-101837-B-100). FIS PI17/01167 received aid from the Instituto de Salud Carlos III, Ministerio de Sanidad, Servicios Sociales e Igualdad. CIBER Fisiología Obesidad y Nutrición (CIBERobn) is an initiative of ISCIII. We thank CERCA Programme/Generalitat de Catalunya for institutional support. Fondo Europeo de Desarrollo Regional (FEDER) "Una manera de hacer Europa"/“a way to build Europe". Investigación subvencionada por la Delegación del Gobierno para el Plan Nacional sobre Drogas (2017I067). Gemma Mestre-Bach was supported by a postdoctoral grant of FUNCIVA.

Acknowledgments: We would like to thank Elena Aragonés Anglada, Inés Llor Del Niño Jesús, Míriam Sanchez Matas, Anaïs Orobitg Puigdomènech, and Patrícia Uriz Ortega for their collaboration in the sample collection.

Conflicts of Interest: The authors declare no conflict of interest.

\section{References}

1. Doornwaard, S.M.; Moreno, M.A.; Van Den Eijnden, R.J.J.M.; Vanwesenbeeck, I.; Ter Bogt, T.F.M. Young adolescents' sexual and romantic reference displays on facebook. J. Adolesc. Health 2014, 55, 535-541. [CrossRef] [PubMed]

2. Vandenbosch, L.; Van Oosten, J.M.F.; Peter, J. The Relationship between Sexual Content on Mass Media and Social Media: A Longitudinal Study. Cyberpsychol. Behav. Soc. Netw. 2015, 18, 697-703. [CrossRef] [PubMed]

3. Wright, P.J. A Longitudinal Analysis of US Adults' Pornography Exposure. J. Media Psychol. 2012, 24, 67-76. [CrossRef]

4. Willoughby, B.J.; Young-Petersen, B.; Leonhardt, N.D. Exploring Trajectories of Pornography Use through Adolescence and Emerging Adulthood. J. Sex Res. 2018, 55, 297-309. [CrossRef] [PubMed]

5. Giordano, A.L.; Cashwell, C.S. Cybersex Addiction among College Students: A Prevalence Study. Sex. Addict. Compuls. 2017, 24, 47-57. [CrossRef]

6. Cooper, A.L. Sexuality and the internet: Surfing into the new millennium. Cyberpsychol. Behav. 1998, 1, 187-193. [CrossRef]

7. Efrati, Y.; Amichai-Hamburger, Y. Are adolescents who consume pornography different from those who engaged in online sexual activities? Child. Youth Serv. Rev. 2020, 111. [CrossRef]

8. Brown, C.C.; Durtschi, J.A.; Carroll, J.S.; Willoughby, B.J. Understanding and predicting classes of college students who use pornography. Comput. Hum. Behav. 2017, 66, 114-121. [CrossRef]

9. Valkenburg, P.M.; Peter, J. The differential susceptibility to media effects model. J. Commun. 2013, 63, 221-243. [CrossRef]

10. Bandura, A. Social Foundations of Thought and Action: Social Cognitive Theory; Prentice Hall: New Jersey, NJ, USA, 1986; ISBN 013815614X.

11. Berkowitz, L. Some effects of thoughts on anti- and prosocial influences of media events: A cognitive-neoassociation analysis. Psychol. Bull. 1984, 95, 410-427. [CrossRef]

12. Klapper, J.T. The Effects of Mass Communication; Free Press: New York, NY, USA, 1960.

13. Steele, J.R.; Brown, J.D. Adolescent room culture: Studying media in the context of everyday life. J. Youth Adolesc. 1995, 24, 551-576. [CrossRef]

14. Peter, J.; Valkenburg, P.M. Adolescents and Pornography: A Review of 20 Years of Research. J. Sex Res. 2016, 53, 509-531. [CrossRef]

15. Ševčíková, A.; Šerek, J.; Barbovschi, M.; Daneback, K. The roles of individual characteristics and liberalism in intentional and unintentional exposure to online sexual material among European youth: A multilevel approach. Sex. Res. Soc. Policy 2014, 11, 104-115. [CrossRef]

16. Mesch, G.S. Social bonds and Internet pornographic exposure among adolescents. J. Adolesc. 2009, 32, 601-618. [CrossRef] [PubMed] 
17. Shek, D.T.L.; Ma, C.M.S. Consumption of pornographic materials among early adolescents in Hong Kong: Profiles and psychosocial correlates. Int. J. Disabil. Hum. Dev. 2012, 11, 143-150. [CrossRef]

18. Wolak, J.; Mitchell, K.; Finkelhor, D. Unwanted and wanted exposure to online pornography in a national sample of youth internet users. Pediatrics 2007, 119, 247-257. [CrossRef]

19. Ybarra, M.L.; Mitchell, K.J. Exposure to Internet pornography among children and adolescents: A national survey. Cyberpsychol. Behav. 2005, 8, 473-486. [CrossRef]

20. Peter, J.; Valkenburg, P.M. Adolescents' exposure to sexually explicit material on the internet. Commun. Res. 2006, 33, 178-204. [CrossRef]

21. Nieh, H.P.; Chang, L.Y.; Chang, H.Y.; Chiang, T.L.; Yen, L.L. Pubertal Timing, Parenting Style, and Trajectories of Pornography Use in Adolescence: Peer Pornography Use as the Mediator. J. Sex Res. 2020, 57, $29-41$. [CrossRef] [PubMed]

22. Shek, D.T.L.; Ma, C.M.S. Using structural equation modeling to examine consumption of pornographic materials in Chinese adolescents in Hong Kong. Int. J. Disabil. Hum. Dev. 2014, 13, 239-245. [CrossRef]

23. Vanden Abeele, M.; Campbell, S.W.; Eggermont, S.; Roe, K. Sexting, Mobile Porn Use, and Peer Group Dynamics: Boys' and Girls' Self-Perceived Popularity, Need for Popularity, and Perceived Peer Pressure. Media Psychol. 2014, 17, 6-33. [CrossRef]

24. Shek, D.T.L.; Ma, C.M.S. A Six-Year Longitudinal Study of Consumption of Pornographic Materials in Chinese Adolescents in Hong Kong. J. Pediatr. Adolesc. Gynecol. 2016, 29, S12-S21. [CrossRef] [PubMed]

25. Efrati, Y.; Amichai-Hamburger, Y. The Use of Online Pornography as Compensation for Loneliness and Lack of Social Ties among Israeli Adolescents. Psychol. Rep. 2019, 122, 1865-1882. [CrossRef] [PubMed]

26. Bekele, A.B.; van Aken, M.A.G.; Dubas, J.S. Sexual violence victimization among female secondary school students in eastern Ethiopia. Violence Vict. 2011, 26, 608-630. [CrossRef] [PubMed]

27. Bonino, S.; Ciairano, S.; Rabaglietti, E.; Cattelino, E. Use of pornography and self-reported engagement in sexual violence among adolescents. Eur. J. Dev. Psychol. 2006, 3, 265-288. [CrossRef]

28. Vega, V.; Malamuth, N.M. Predicting sexual aggression: The role of pornography in the context of general and specific risk factors. Aggress. Behav. 2007, 33, 104-117. [CrossRef]

29. Efrati, Y. Problematic and Non-problematic Pornography Use and Compulsive Sexual Behaviors among Understudied Populations: Children and Adolescents. Curr. Addict. Rep. 2020, 7, 68-75. [CrossRef]

30. Maas, M.K.; Bray, B.C.; Noll, J.G. Online Sexual Experiences Predict Subsequent Sexual Health and Victimization Outcomes among Female Adolescents: A Latent Class Analysis. J. Youth Adolesc. 2019, 48, 837-849. [CrossRef]

31. Brown, J.D.; L'Engle, K.L. X-rated: Sexual attitudes and behaviors associated with U.S. early adolescents' exposure to sexually explicit media. Commun. Res. 2009, 36, 129-151. [CrossRef]

32. Doornwaard, S.M.; Bickham, D.S.; Rich, M.; ter Bogt, T.F.M.; van den Eijnden, R.J.J.M. Adolescents' use of sexually explicit internet material and their sexual attitudes and behavior: Parallel development and directional effects. Dev. Psychol. 2015, 51, 1476-1488. [CrossRef]

33. Lo, V.H.; Wei, R. Exposure to internet pornography and Taiwanese adolescents' sexual attitudes and behavior. J. Broadcast. Electron. Media 2005, 49, 221-237. [CrossRef]

34. Peter, J.; Valkenburg, P.M. The influence of sexually explicit internet material on sexual risk behavior: A comparison of adolescents and adults. J. Health Commun. 2011, 16, 750-765. [CrossRef] [PubMed]

35. Luder, M.T.; Pittet, I.; Berchtold, A.; Akré, C.; Michaud, P.A.; Surís, J.C. Associations between online pornography and sexual behavior among adolescents: Myth or reality? Arch. Sex. Behav. 2011, 40, 1027-1035. [CrossRef] [PubMed]

36. Stata-Corp Stata Statistical Software; Release 16; Stata-Corp: College Station, TX, USA, 2019.

37. Kleinbaum, D.G.; Kupper, L.L.; Müller, K.E.; Nizam, A. Applied Regression Analysis and Other Multivariable Methods; Duxbury Applied Press: Pacific Grove, CA, USA, 2013.

38. Cohen, J.; Miles, J.; Shevlin, M. Applying Regression and Correlation: A Guide for Students and Researchers; SAGE Publications Inc.: London, UK, 2001.

39. Steyerberg, E.W.; Harrell, F.E.; Borsboom, G.J.J.M.; Eijkemans, M.J.C.; Vergouwe, Y.; Habbema, J.D.F. Internal validation of predictive models: Efficiency of some procedures for logistic regression analysis. J. Clin. Epidemiol. 2001, 54, 774-781. [CrossRef]

40. Kline, R.B. Principles and Practice of Structural Equation Modeling, 2nd ed.; The Guilford Press: New York, NY, USA, 2005. 
41. MacCallum, R.C.; Austin, J.T. Applications of structural equation modeling in psychological research. Annu. Rev. Psychol. 2000, 51, 201-226. [CrossRef]

42. von Oertzen, T. Power equivalence in structural equation modelling. Br. J. Math. Stat. Psychol. 2010, 63, 257-272. [CrossRef]

43. Borsboom, D.; Mellenbergh, G.J.; Van Heerden, J. The Theoretical Status of Latent Variables. Psychol. Rev. 2003, 110, 203-219. [CrossRef]

44. Barrett, P. Structural equation modelling: Adjudging model fit. Pers. Individ. Differ. 2007, 42, 815-824. [CrossRef]

45. Copen, C.E.; Chandra, A.; Febo-Vazquez, I. Sexual behavior, sexual attraction, and sexual orientation among adults aged 18-44 in the United States from 2011-2013. Natl. Health Stat. Rep. 2016, 88, 1-14.

46. Hsieh, N.; Ruther, M. Sexual Minority Health and Health Risk Factors: Intersection Effects of Gender, Race, and Sexual Identity. Am. J. Prev. Med. 2016, 50, 746-755. [CrossRef]

47. Phillips, G.; Beach, L.B.; Turner, B.; Feinstein, B.A.; Marro, R.; Philbin, M.M.; Salamanca, P.; Felt, D.; Birkett, M. Sexual Identity and Behavior Among U.S. High School Students, 2005-2015. Arch. Sex. Behav. 2019, 48, 1463-1479. [CrossRef] [PubMed]

48. Li, Y.; Yuan, Z.; Clements-Nolle, K.; Yang, W. Sexual Orientation and Depressive Symptoms among High School Students in Jiangxi Province. Asia-Pac. J. Public Health 2018, 30, 635-643. [CrossRef] [PubMed]

49. Neymotin, F.; Downing-Matibag, T.M. Religiosity and Adolescents' Involvement with Both Drugs and Sex. J. Relig. Health 2013, 52, 550-569. [CrossRef] [PubMed]

50. de Mexico, F.G. Encuesta Nacional de Juventud 2010: Resultados Generales [National Survey of Youth 2010: General Results]; Secretaria de Educacion Publica: Mexico City, Mexico, 2010.

51. Nwagu, E.N. Alcohol and drug usage; and adolescents' sexual behaviour in Nigeria. Health Promot. Int. 2016, 31, 405-413. [CrossRef]

52. McCarty-Caplan, D.; Jantz, I.; Swartz, J. MSM and drug use: A latent class analysis of drug use and related sexual risk behaviors. AIDS Behav. 2014, 18, 1339-1351. [CrossRef]

53. Riva, K.; Allen-Taylor, L.; Schupmann, W.D.; Mphele, S.; Moshashane, N.; Lowenthal, E.D. Prevalence and predictors of alcohol and drug use among secondary school students in Botswana: A cross-sectional study. BMC Public Health 2018, 18. [CrossRef]

54. Antunes, H.D.; Rivadeneira-Guerrero, M.F.; de Goulart, B.N.G.; Oenning, N.S.X. Familiar factors and illicit drug use among brazilian adolescents: An analysis of the Brazilian national survey of school health (peNSE, 2015). Cad. Saude Publica 2018, 34. [CrossRef]

55. Park, S.; Kim, Y. Prevalence, correlates, and associated psychological problems of substance use in Korean adolescents. BMC Public Health 2016, 16. [CrossRef]

56. Vaughn, M.G.; Nelson, E.J.; Oh, S.; Salas-Wright, C.P.; DeLisi, M.; Holzer, K.J. Abstention from Drug Use and Delinquency Increasing among Youth in the United States, 2002-2014. Subst. Use Misuse 2018, 53, 1468-1481. [CrossRef]

57. Simon, L.; Daneback, K. Adolescents' Use of the Internet for Sex Education: A Thematic and Critical Review of the Literature. Int. J. Sex. Health 2013, 25, 305-319. [CrossRef]

58. Aicken, C.R.H.; Estcourt, C.S.; Johnson, A.M.; Sonnenberg, P.; Wellings, K.; Mercer, C.H. Use of the Internet for Sexual Health Among Sexually Experienced Persons Aged 16 to 44 Years: Evidence from a Nationally Representative Survey of the British Population. J. Med. Internet Res. 2016, 18, e14. [CrossRef] [PubMed]

59. Patterson, S.P.; Hilton, S.; Flowers, P.; Mcdaid, L.M. What are the barriers and challenges faced by adolescents when searching for sexual health information on the internet? Implications for policy and practice from a qualitative study. Sex. Transm. Infect. 2019, 95, 462-467. [CrossRef] [PubMed]

60. Borges, A.L.V.; Fujimori, E.; Kuschnir, M.C.C.; Do Nascimento Chofakian, C.B.; De Moraes, A.J.P.; Azevedo, G.D.; Dos Santos, K.F.; De Vasconcellos, M.T.L. ERICA: Sexual initiation and contraception in Brazilian adolescents. Rev. Saude Publica 2016, 50,1s-11s. [CrossRef]

61. Morgan, A.; Saunders, B.; Dodge, B.; Harper, G.; Arrington Sanders, R. Exploring the Sexual Development Experiences of Black Bisexual Male Adolescents Over Time. Arch. Sex. Behav. 2018, 47, 1839-1851. [CrossRef] [PubMed]

62. Vandenbosch, L.; Beyens, I.; Vangeel, L.; Eggermont, S. Online communication predicts Belgian adolescents' initiation of romantic and sexual activity. Eur. J. Pediatr. 2016, 175, 509-516. [CrossRef] [PubMed] 
63. Young, H.; Burke, L.; Nic Gabhainn, S. Sexual intercourse, age of initiation and contraception among adolescents in Ireland: Findings from the Health Behaviour in School-aged Children (HBSC) Ireland study. BMC Public Health 2018, 18. [CrossRef]

64. Chan, C.H.; Ting, T.T.; Chen, Y.T.; Chen, C.Y.; Chen, W.J. Sexual Initiation and Emotional/Behavioral Problems in Taiwanese Adolescents: A Multivariate Response Profile Analysis. Arch. Sex. Behav. 2015, 44, 717-727. [CrossRef]

65. Arnarsson, Á.M.; Gísladóttir, K.H.; Jónsson, S.H. The prevalence of sexual abuse and sexual assault against icelandic adolescents. Laeknabladid 2016, 102, 289-295. [CrossRef]

66. Ricardo, C.; Eads, M.; Barker, G.T. Engaging Men and Boys in Pthe Prevention of Sexual Violence: A Systematic and Global Review of Evaluated Interventions; 2011; Available online: https://promundoglobal.org/resources/engaging-boys-and-young-men-in-the-prevention-of-sexual -violence-a-systematic-and-global-review-of-evaluated-interventions/\# (accessed on 30 September 2020).

67. Lundgren, R.; Amin, A. Addressing intimate partner violence and sexual violence among adolescents: Emerging evidence of effectiveness. J. Adolesc. Health 2014, 56, S42-S50. [CrossRef]

68. Mori, C.; Temple, J.R.; Browne, D.; Madigan, S. Association of Sexting with Sexual Behaviors and Mental Health among Adolescents: A Systematic Review and Meta-analysis. JAMA Pediatr. 2019, 173, 770-779. [CrossRef]

69. Gassó, A.M.; Klettke, B.; Agustina, J.R.; Montiel, I. Sexting, mental health, and victimization among adolescents: A literature review. Int. J. Environ. Res. Public Health 2019, 16, 2364. [CrossRef] [PubMed]

70. Titchen, K.E.; Maslyanskaya, S.; Silver, E.J.; Coupey, S.M. Sexting and Young Adolescents: Associations with Sexual Abuse and Intimate Partner Violence. J. Pediatr. Adolesc. Gynecol. 2019, 32, 481-486. [CrossRef] [PubMed]

71. Mattebo, M.; Tydén, T.; Häggström-Nordin, E.; Nilsson, K.W.; Larsson, M. Pornography consumption, sexual experiences, lifestyles, and self-rated health among male adolescents in Sweden. J. Dev. Behav. Pediatr. 2013, 34, 460-468. [CrossRef] [PubMed]

72. Lim, M.S.C.; Agius, P.A.; Carrotte, E.R.; Vella, A.M.; Hellard, M.E. Young Australians' use of pornography and associations with sexual risk behaviours. Aust. N. Z. J. Public Health 2017, 41, 438-443. [CrossRef] [PubMed]

73. Dwulit, A.D.; Rzymski, P. Prevalence, patterns and self-perceived effects of pornography consumption in polish university students: A cross-sectional study. Int. J. Environ. Res. Public Health 2019, 16, 1861. [CrossRef]

74. Romito, P.; Beltramini, L. Watching pornography: Gender differences, violence and victimization. An exploratory study in Italy. Violence Women 2011, 17, 1313-1326. [CrossRef]

75. Anisimowicz, Y.; O'Sullivan, L.F. Men's and Women's Use and Creation of Online Sexually Explicit Materials Including Fandom-Related Works. Arch. Sex. Behav. 2017, 46, 823-833. [CrossRef]

76. Strahler, J.; Kruse, O.; Wehrum-Osinsky, S.; Klucken, T.; Stark, R. Neural correlates of gender differences in distractibility by sexual stimuli. Neuroimage 2018, 176, 499-509. [CrossRef]

77. Rupp, H.A.; Wallen, K. Sex differences in response to visual sexual stimuli: A review. Arch. Sex. Behav. 2008, 37, 206-218. [CrossRef]

78. Wright, P.J.; Bae, S.; Funk, M. United States women and pornography through four decades: Exposure, attitudes, behaviors, individual differences. Arch. Sex. Behav. 2013, 42, 1131-1144. [CrossRef]

79. Fritz, N.; Paul, B. From Orgasms to Spanking: A Content Analysis of the Agentic and Objectifying Sexual Scripts in Feminist, for Women, and Mainstream Pornography. Sex Roles 2017, 77, 639-652. [CrossRef]

80. Peter, J.; Valkenburg, P.M. The use of sexually explicit internet material and its antecedents: A longitudinal comparison of adolescents and adults. Arch. Sex. Behav. 2011, 40, 1015-1025. [CrossRef] [PubMed]

81. Wright, P.J. Pornography consumption, cocaine use, and casual sex among U.S. adults. Psychol. Rep. 2012, 111, 305-310. [CrossRef] [PubMed]

82. Grubbs, J.B.; Perry, S.L. Moral Incongruence and Pornography Use: A Critical Review and Integration. J. Sex Res. 2019, 56, 29-37. [CrossRef] [PubMed]

83. Grubbs, J.B.; Perry, S.L.; Wilt, J.A.; Reid, R.C. Pornography Problems Due to Moral Incongruence: An Integrative Model with a Systematic Review and Meta-Analysis. Arch. Sex. Behav. 2019, 48, 397-415. [CrossRef] 
84. Kohut, T.; Štulhofer, A. The Role of Religiosity in Adolescents' Compulsive Pornography Use: A Longitudinal Assessment. J. Sex Marital Ther. 2018, 44, 759-775. [CrossRef]

85. Rasmussen, K.; Bierman, A. How does religious attendance shape trajectories of pornography use across adolescence? J. Adolesc. 2016, 49, 191-203. [CrossRef]

86. Braun-Courville, D.K.; Rojas, M. Exposure to Sexually Explicit Web Sites and Adolescent Sexual Attitudes and Behaviors. J. Adolesc. Health 2009, 45, 156-162. [CrossRef]

Publisher's Note: MDPI stays neutral with regard to jurisdictional claims in published maps and institutional affiliations.

(C) 2020 by the authors. Licensee MDPI, Basel, Switzerland. This article is an open access article distributed under the terms and conditions of the Creative Commons Attribution (CC BY) license (http://creativecommons.org/licenses/by/4.0/). 